\title{
Association between Gastric Cancer with Behavioral and Dietary Factors: A Hospital Based Case-Control Study in South Asia
}

\author{
Arun Shahi10 Venkata Pradeep Babu Koyyala20 Ela Singh Rathaur ${ }^{3}$ Md. Assaduzaman Biddut ${ }^{4}$ \\ Anwor Hossain ${ }^{4}$ Md. Kamrul Hasan ${ }^{4}$ Jahangir Alam ${ }^{4}$ Tanzina Hossain ${ }^{4}$ Nazrina Khatun ${ }^{4}$
}

\footnotetext{
${ }^{1}$ Medical Oncology Unit, Faculty of Internal Medicine, Patan Academy of Health Science, Lalitpur, Nepal

2 Medical Oncology, Assam Cancer Care Foundation, Assam, India

${ }^{3}$ Department of Clinical Epidemiology and Biostatistics, Faculty of Medicine, Ramathibodi Hospital, Mahidol University, Thailand

${ }^{4}$ Department of Medical Oncology, National Institute of Cancer Research and Hospital, Mohakhali, Dhaka, Bangladesh
}

\author{
Address for correspondence Arun Shahi, MD, MPH, Medical \\ Oncology, Assam Cancer Care Foundation, Tezpur, Assam 784153, \\ India (e-mail: arunshahi@pahs.edu.np).
}

Asian J Oncol

\begin{abstract}
Keywords

- gastric cancer

- behavioral factors

- dietary factors

Background Gastric cancer (GC) is one of the most common malignancies and a leading cause of mortality and morbidity worldwide. It is the fourth leading cancer in Bangladesh. Identification of risk factors, effective prevention, and early diagnosis are the most important interventions against GC.

Objectives To find an association of dietary and behavioral factors in the development of GC among the Bangladeshi population.

Methods This case-control study was conducted from January 2017 to December 2018 at the National Institute of Cancer Research and Hospital, Dhaka, Bangladesh. A total of 178 patients were studied ( 89 case and 89 controls). Data were collected via face-to-face interview using a standard structured questionnaire, posing questions about socio-demographic, behavioral and dietary habits, and clinical factors. A binary logistic regression method was used to calculate the odds ratio (OR).

Results Among 178 patients, the age group ranged from 30 to 80 years and most patients were between 51 to 60 years. The results showed that regular consumption of red meat, duration of smoking, smokeless tobacco, fast food and fatty food, and family history of any type of cancer were directly associated with the risk of GC. On the contrary, a habit of regular walking and playing sports has an inverse association with GC. Adjusted OR shows regular consumption of red meat has 2.6 times more risk $(O R=2.661)$ of developing GC compared with irregular meat consumption, and a person with a history of Helicobacter pylori infection is $53 \%(O R=7.263 ; 95 \%$ confidence interval: 3.614-14.597) more likely to develop cancer. In contrast, people who were doing exercise regularly for at least 30 minutes/day are $62.7 \%(O R=0.373)$ less likely to develop GC than those who did not.
\end{abstract}

DOI https://doi.org/ 10.1055/s-0041-1740106. ISSN 2454-6798.
(C) 2021. Spring Hope Cancer Foundation \& Young Oncologist Group of Asia. All rights reserved.

This is an open access article published by Thieme under the terms of the Creative Commons Attribution-NonDerivative-NonCommercial-License, permitting copying and reproduction so long as the original work is given appropriate credit. Contents may not be used for commercial purposes, or adapted, remixed, transformed or built upon. (https://creativecommons.org/ licenses/by-nc-nd/4.0/)

Thieme Medical and Scientific Publishers Pvt. Ltd., A-12, 2nd Floor, Sector 2, Noida-201301 UP, India 
Conclusion The study showed an association of some dietary and behavioral factor in the development of GC. However, more research in this field is required to understand the etiology, for the development of suitable screening test, for demarcation of highrisk population, and to develop and evaluate the effectiveness of primary prevention programs.

\section{Introduction}

Gastric cancer (GC) is the fourth most common cancer worldwide and the second most common cause of cancerrelated deaths. ${ }^{1}$ It is one of the important malignancies that cause widespread morbidity and mortality. Similar to other Asian countries, GC is also a leading cancer in Bangladesh. ${ }^{2}$ According to the International Gastric Cancer Society, more than 800,000 people are affected by GC every year and up to 650,000 people have succumbed to $\mathrm{GC}^{3}$

GC remains an important burden for public health, particularly in less developed countries including Middle and Eastern Asia, South America, and Eastern Europe, being responsible for $70 \%$ of cases worldwide. ${ }^{4,5}$ Mortality rates remain high as it is usually detected late in its course when treatment strategies are often not beneficial. GC is a multifactorial disease, where both environmental and genetic factors might have an impact on its occurrence, development, and progression. Therefore, primary prevention and early detection remain the most important public health interventions. However, these strategies require identification and understanding of risk factors that lead to carcinogenesis. ${ }^{6}$ Although the incidence of GC is declining in developed countries over the last few decades, the incidence in developing countries is still high. ${ }^{7}$ Similarly, the prevalence of GC is high in Bangladesh. According to the cancer registry of the National Institute of Cancer Research and Hospital (NICRH) of Bangladesh, GC is the fifth common cancer and in 2015 only, 354 cases of GC were registered among which almost all cases were diagnosed in advanced stage. $^{8}$

\section{Materials and Methods}

This case-control study was performed at NIRCH, Mohakhali, Dhaka, from January 2017 to December 2018. A purposive sampling technique was applied to select cases for this study. All patients with endoscopically and histopathologically proven adenocarcinoma of the stomach admitted under the Medical Oncology department of NICRH were included in this study. We excluded patients with cognitive problems, terminally ill patients, and incomplete medical records. Case: patients with diagnosed case of GC (histopathology proved). Control: patients without GC but with other cancer (histopathology proved). Cases were selected from the Department of Medical Oncology and controls were recruited from Medical Oncology and other departments of NICRH. Data were collected by face-to-face interviews using standardized semistructured questionnaires. The questionnaire was developed after expert discussion and literature review in both Bengali and English languages. It was pretested for face and content validity and reliability, which were satisfactory (Cronbach's alpha: 0.63-0.92). Research instruments were prepared by using the selected variables according to objectives. The questionnaire included socio-demography, dietary, behavioral and clinical history. At the prescreening, the patient's family history was also taken, and laboratory reports, histopathology reports, and colonoscopy reports of the last 3 months were reviewed. The research had been approved by the Research and Ethical Committee of NICRH. Respondents were explained about the research and asked for consent before the interview. All information is confidential and individual data had no identification of the respondents.

Data were analyzed by using Statistical Package for Social Sciences (SPSS) for windows version 23. Data were described using frequency for categorical data, the mean values were appropriate for continuous data. The data were checked for accuracy and completeness. $p$-Values of $<0.05$ were considered statistically significant. The results were presented in tables, graphs, and charts. The Chi-square test was used to analyze the categorical variables shown with cross-tabulation. Student's t-test was used for continuous variables. Binary logistic regression analysis was used for risk factors of GC among the adult Bangladeshi population.

\section{Results}

A total of 178 patients were studied (89 cases and 89 controls) in this unmatched case-control study. The subjects were between the age group of 30 and 80 years. The findings derived from data analysis are presented in the given section below.

- Table 1 shows the association of socio-demographic characteristics of the patients to GC status, which suggested that males were $0.5 \%$ less likely to have GC compared with females, though $76.4 \%$ of cases were males and statistically significant. Again compared with married, the unmarried/divorced persons were $28 \%$ less likely, and compared with unemployed, employed and business persons were 56 and 70\% less likely to develop GC, respectively. Similarly, compared with lower income, middle- and highincome people were 0.25 and 0.4 times less likely to have GC. However, these results were statistically not significant. - Table 2 shows the behavioral and smoking status of the participants, which suggested that patients who were current smoker were two times more likely (odds ratio $[\mathrm{OR}]=2.23$ ) to have GC compared with those 
Association between GC with Behavioral and Dietary Factors Shahi et al.

Table 1 Socio-demographic characteristics of the patient and unadjusted odds ratio of each covariate and case-control

\begin{tabular}{|c|c|c|c|c|c|c|}
\hline \multirow[t]{2}{*}{ Variables } & \multicolumn{2}{|c|}{ Case $(n=89)$} & \multicolumn{2}{|c|}{ Control $(n=89)$} & \multirow{2}{*}{$\begin{array}{l}\text { Unadjusted odd ratio } \\
\text { (CI) }\end{array}$} & \multirow[t]{2}{*}{$p$-Value } \\
\hline & Number & Per cent $\%$ & Number & Per cent $\%$ & & \\
\hline \multicolumn{7}{|l|}{ Gender } \\
\hline Male & 68 & 76.4 & 55 & 61.8 & $\begin{array}{l}0.500 \\
(0.261-0.957)\end{array}$ & \multirow[t]{2}{*}{0.058} \\
\hline Female & 21 & 23.6 & 34 & 38.2 & Reference & \\
\hline \multicolumn{7}{|l|}{ Age } \\
\hline$<50 y$ & 20 & 22.5 & 27 & 30.3 & Reference & \multirow[t]{2}{*}{0.31} \\
\hline$>50 y$ & 69 & 77.5 & 62 & 69.7 & $\begin{array}{l}1.562 \\
(0.767-2.943)\end{array}$ & \\
\hline \multicolumn{7}{|l|}{ Marital status } \\
\hline Married & 80 & 89.9 & 77 & 86.5 & $\begin{array}{l}0.722 \\
(0.288-1.810)\end{array}$ & \multirow[t]{2}{*}{0.64} \\
\hline Unmarried/divorce & 9 & 10.1 & 12 & 13.5 & Reference & \\
\hline \multicolumn{7}{|l|}{ Education level } \\
\hline Illiterate (below 5 years of school) & 58 & 65.2 & 61 & 68.5 & $\begin{array}{l}1.164 \\
(0.623-2.175)\end{array}$ & \multirow[t]{2}{*}{0.75} \\
\hline Literate (above 5 years of school) & 31 & 34.8 & 28 & 31.5 & Reference & \\
\hline \multicolumn{7}{|l|}{ Occupation } \\
\hline Unemployed & 29 & 32.6 & 24 & 27.0 & Reference & \\
\hline Employed & 40 & 44.9 & 57 & 64.0 & $\begin{array}{l}0.441 \\
(0.108-1.804)\end{array}$ & 0.15 \\
\hline Business & 20 & 22.5 & 8 & 9.0 & $\begin{array}{l}0.306 \\
(1.140-8.204)\end{array}$ & 0.01 \\
\hline \multicolumn{7}{|l|}{ Monthly income } \\
\hline$<15,000$ & 12 & 13.5 & 16 & 18 & $0.004(0.072-0.599)$ & 0.15 \\
\hline $15,000-40,000$ & 72 & 80.9 & 52 & 41.9 & $\begin{array}{l}0.250 \\
(0.158-1.619)\end{array}$ & 0.07 \\
\hline$>40,000$ & 5 & 5.6 & 21 & 23.6 & Reference & \\
\hline
\end{tabular}

Abbreviation: $\mathrm{Cl}$, confidence interval.

Table 2 Behavioral and smoking status of the patients and unadjusted odds ratio of each covariate and case-control

\begin{tabular}{|c|c|c|c|c|c|c|}
\hline \multirow[t]{2}{*}{ Variables } & \multicolumn{2}{|c|}{ Case $(n=89)$} & \multicolumn{2}{|c|}{ Control $(n=89)$} & \multirow{2}{*}{$\begin{array}{l}\text { Unadjusted OR } \\
\text { (CI) }\end{array}$} & \multirow[t]{2}{*}{$p$-Value } \\
\hline & Number & Per cent \% & Number & Per cent \% & & \\
\hline \multicolumn{7}{|l|}{ Smoking status } \\
\hline No & 23 & 25.8 & 39 & 43.8 & Reference & \multirow[t]{2}{*}{0.18} \\
\hline Yes & 66 & 74.2 & 50 & 56.2 & $\begin{array}{l}2.238 \\
(1.189-4.215)\end{array}$ & \\
\hline \multicolumn{7}{|l|}{ Smokeless tobacco } \\
\hline No & 32 & 36.0 & 47 & 52.8 & Reference & \multirow[t]{2}{*}{0.34} \\
\hline Yes & 57 & 64.0 & 42 & 47.2 & $\begin{array}{l}1.993 \\
(1.093-3.634)\end{array}$ & \\
\hline \multicolumn{7}{|l|}{ Alcohol intake } \\
\hline No & 70 & 78.7 & 74 & 83.1 & Reference & \multirow[t]{2}{*}{0.57} \\
\hline Yes & 19 & 21.3 & 15 & 16.9 & $\begin{array}{l}1.339 \\
(0.631-2.840)\end{array}$ & \\
\hline \multicolumn{7}{|l|}{ Exercise habit } \\
\hline Yes $(>30 \mathrm{~min} / \mathrm{d})$ & 66 & 74.2 & 46 & 51.7 & Reference & \\
\hline No $(=$ or $<30 \mathrm{~min} / \mathrm{d})$ & 23 & 25.8 & 43 & 48.3 & $\begin{array}{l}0.373 \\
(0.198-0.701)\end{array}$ & $<0.01$ \\
\hline
\end{tabular}

Abbreviations: $\mathrm{Cl}$, confidence interval; OR, odds ratio. 
Association between GC with Behavioral and Dietary Factors Shahi et al.

Table 3 Dietary patterns of the patients and unadjusted odds ratio of each covariate and case-control

\begin{tabular}{|c|c|c|c|c|c|c|}
\hline \multirow[t]{2}{*}{ Variables } & \multicolumn{2}{|c|}{ Case $(n=89)$} & \multicolumn{2}{|c|}{ Control $(n=89)$} & \multirow[t]{2}{*}{ Unadjusted odd ratio $(\mathrm{Cl})$} & \multirow[t]{2}{*}{$p$-Value } \\
\hline & Number & Per cent \% & Number & Per cent \% & & \\
\hline \multicolumn{7}{|l|}{ Red meat consumption } \\
\hline Yes (= or $>2$ times/wk) & 38 & 42.7 & 19 & 21.3 & $\begin{array}{l}2.745 \\
(1.421-5.303)\end{array}$ & \multirow[t]{2}{*}{$<0.01$} \\
\hline No (<2 times/wk) & 51 & 57.3 & 70 & 78.7 & Reference & \\
\hline \multicolumn{7}{|l|}{ Chicken meat } \\
\hline Yes (= or $>2$ times/wk) & 20 & 22.5 & 14 & 15.7 & $\begin{array}{l}1.553 \\
0.728-3.311)\end{array}$ & \multirow[t]{2}{*}{0.34} \\
\hline No (<2 times/wk) & 69 & 77.5 & 75 & 84.3 & Reference & \\
\hline \multicolumn{7}{|l|}{ Fish intake } \\
\hline Yes $(=$ or $>2$ times/wk) & 59 & 66.3 & 51 & 57.3 & Reference & \multirow[t]{2}{*}{0.28} \\
\hline No (<2 times/wk) & 30 & 33.7 & 38 & 42.7 & $\begin{array}{l}1.465 \\
(0.798-2.691)\end{array}$ & \\
\hline \multicolumn{7}{|l|}{ Vegetables } \\
\hline Yes $(=$ or $>2$ times/wk) & 81 & 91.0 & 78 & 87.6 & Reference & \multirow[t]{2}{*}{0.63} \\
\hline No (<2 times/wk) & 8 & 9.0 & 11 & 12.4 & $\begin{array}{l}1.428 \\
(0.545-3.738)\end{array}$ & \\
\hline \multicolumn{7}{|l|}{ Fast food } \\
\hline Yes (= or $>2$ times/wk) & 23 & 25.8 & 8 & 9.0 & $\begin{array}{l}3.528 \\
(1.482-8.402)\end{array}$ & \multirow[t]{2}{*}{$<0.01$} \\
\hline No (<2 times/wk) & 66 & 74.2 & 81 & 91.0 & Reference & \\
\hline
\end{tabular}

Abbreviation: $\mathrm{Cl}$, confidence interval.

who were not current smokers. Again, those persons who were habituated with smokeless tobacco products were found to have 1.9 times higher risk compared with nonconsumers. But these were not statistically significant. Persons who regularly exercise at least 30 minutes per day were found to be less likely to develop GC compared with those who did not exercise. However, current walking habit was found to have a significant inverse relationship with GC. - Table 3 shows the association of dietary patterns of the patients to stomach GC, which suggested that regular consumption of red meat had a significant association in the development of GC, i.e., red meat consumers were 2.74 times more likely to develop GC as compared with no/irregular consumers. This was also true for consumption of fast food, i.e., regular fast food consumers were 3.5 times more likely to develop GC when compared with those who consumed less than two times per week. Moreover, those persons who intake chicken meat were found to be 1.5 more likely and consumption of fish found were found to be 1.4 times less likely to develop GC compared with nonconsumers, but not statistically significant, and consumption of regular vegetables was found to be 1.4 times less likely to develop GC compared with nonconsumers, but not statistically significant. - Table 4 shows the clinical history of the participants, which suggested that family history of any type of cancer has a significant association with the development of

Table 4 Clinical history of the patients and unadjusted odds ratio of each covariate and case-control

\begin{tabular}{|c|c|c|c|c|c|c|}
\hline \multirow[t]{2}{*}{ Variables } & \multicolumn{2}{|c|}{ Case $(n=89)$} & \multicolumn{2}{|c|}{ Control $(n=89)$} & \multirow{2}{*}{$\begin{array}{l}\text { Unadjusted odds ratio } \\
\text { (CI) }\end{array}$} & \multirow[t]{2}{*}{$p$-Value } \\
\hline & Number & Per cent \% & Number & Per cent \% & & \\
\hline \multicolumn{7}{|c|}{ Family history } \\
\hline Yes & 32 & 36.0 & 20 & 22.5 & $\begin{array}{l}1.937 \\
(1.001-3.746)\end{array}$ & \multirow[t]{2}{*}{0.07} \\
\hline No & 57 & 64.0 & 69 & 77.5 & Reference & \\
\hline \multicolumn{7}{|l|}{ H. pylori } \\
\hline Yes & 53 & 59.6 & 15 & 16.9 & $\begin{array}{l}7.263 \\
(3.614-14.597)\end{array}$ & \multirow[t]{2}{*}{$<0.01$} \\
\hline No & 36 & 40.7 & 74 & 83.1 & Reference & \\
\hline
\end{tabular}

Abbreviation: $\mathrm{Cl}$, confidence interval. 
Association between GC with Behavioral and Dietary Factors Shahi et al.

Table 5 Blood groups of the patient and unadjusted odds ratio of different types of blood group and case-control

\begin{tabular}{|c|c|c|c|c|c|c|}
\hline \multirow[t]{2}{*}{ Variables } & \multicolumn{2}{|c|}{ Case $(n=89)$} & \multicolumn{2}{|c|}{ Control $(n=89)$} & \multirow{2}{*}{$\begin{array}{l}\text { Unadjusted odds ratio } \\
\text { (confidence interval) }\end{array}$} & \multirow[t]{2}{*}{$p$-Value } \\
\hline & Number & Per cent \% & Number & Per cent \% & & \\
\hline \multicolumn{7}{|c|}{ Blood group } \\
\hline $\mathrm{O}$ & 13 & 14.6 & 27 & 30.3 & Reference & Reference \\
\hline$A$ & 42 & 47.2 & 9 & 10.1 & $\begin{array}{l}9.692 \\
(3.646-25.768)\end{array}$ & $<0.05$ \\
\hline B & 15 & 16.9 & 28 & 31.5 & $\begin{array}{l}1.113 \\
(0.447-2.769)\end{array}$ & 0.81 \\
\hline$A B$ & 19 & 21.3 & 25 & 28.1 & $\begin{array}{l}1.578 \\
(0.648-3.847)\end{array}$ & 0.31 \\
\hline
\end{tabular}

GC, i.e., persons who had positive family history were 1.9 times more likely to develop GC compared with negative family history. Moreover, people who suffered from $\mathrm{H}$. pyloric infection were 7.2 times significantly more likely to develop GC. - Table 5 shows the ABO blood group distribution of the participants. Here, unadjusted OR suggested that blood group A has a significant association with the devel- opment of stomach cancer, i.e., blood group A were nine times significantly more likely to develop GC compared with other ABO blood group type. The other ABO blood groups are not statistically significant with GC. - Table 6 shows the adjusted OR, which suggested that most of the variables had a minimal difference in their adjusted OR showing that there is a significant association between gender (crude OR of 0.51

Table 6 Adjusted and unadjusted OR with different variables

\begin{tabular}{|c|c|c|c|c|}
\hline \multirow[t]{2}{*}{ Variables } & \multicolumn{2}{|c|}{ Unadjusted analysis } & \multicolumn{2}{|c|}{ Adjusted analysis } \\
\hline & Odds ratio & $95 \% \mathrm{Cl}$ & Odds Ratio & $95 \% \mathrm{Cl}$ \\
\hline \multicolumn{5}{|l|}{ Gender } \\
\hline Male & 0.51 & $0.261-0.957$ & 0.50 & $0.230-0.850$ \\
\hline Female & 1 & & 1 & \\
\hline \multicolumn{5}{|l|}{ Red meat } \\
\hline No & 1 & & 1 & \\
\hline Yes & 2.745 & $1.421-5.303$ & 2.661 & $1.331-5.320$ \\
\hline \multicolumn{5}{|l|}{ Fast food } \\
\hline No & 1 & & 1 & \\
\hline Yes & 3.528 & $1.482-8.402$ & 1.393 & $0.470-4.134$ \\
\hline \multicolumn{5}{|l|}{ Smoking status } \\
\hline No & 1 & & 1 & \\
\hline Yes & 2.23 & $1.189-4.215$ & 1.545 & $0.685-3.483$ \\
\hline \multicolumn{5}{|l|}{ Smokeless tobacco } \\
\hline No & 1 & & 1 & \\
\hline Yes & 1.993 & $1.093-3.634$ & 1.658 & $0.735-3.738$ \\
\hline \multicolumn{5}{|l|}{ Exercise habit } \\
\hline$>30 \mathrm{~min} / \mathrm{d}$ & 1 & & 1 & \\
\hline$=$ or $<30 \mathrm{~min} / \mathrm{d}$ & 1.87 & $1.127-3.102$ & 0.84 & $0.041-0.172$ \\
\hline \multicolumn{5}{|l|}{ H. pylori } \\
\hline No & 1 & & 1 & \\
\hline Yes & 7.263 & $3.614-14.597$ & 6.736 & $2.812-16.139$ \\
\hline \multicolumn{5}{|l|}{ Blood group A } \\
\hline No & 1 & & 1 & \\
\hline Yes & 9.692 & $3.64-25.76$ & 0.132 & $0.059-0.295$ \\
\hline
\end{tabular}

Abbreviation: $\mathrm{Cl}$, confidence interval. 
compared with adjusted OR of 0.50), regular red meat consumption (crude OR of 2.74 compared with adjusted OR of 2.661), and prior infection with $H$. pylori (crude OR of 7.263 compared with adjusted OR of 6.73) with GC.

\section{Discussion}

GC is one of the leading cause of malignancies worldwide. Despite its declining incidence in developed countries, it remains an important public health burden in resourceconstraint countries like Bangladesh, likely due to sustenance by environmental risk factors, both known and unknown. Our study found that GC is more prevalent in males than in females, which is similar to previous research studies conducted in Bangladesh. ${ }^{8}$ Our socio-demographic analysis suggested that the risk of GC is inversely related to the level of education, i.e., the literate group was less likely to develop GC, which is similar to a previous study ${ }^{9}$ that also suggested that participants with higher degree or diplomas were more self-conscious and indulged in physical activity. ${ }^{9}$ This might be because literate people are usually more aware of their health condition and follow a discipline life. Similarly, our study also suggested that the risk of GC is less among employed and business people compared with unemployed. This might be because our study included recently retired and aged people which might have diluted the results. ${ }^{10}$ Also, as employed people are more active which might have aided in achieving health-related fitness. Besides, the study showed a nonsignificant association of monthly household income with the development of GC, which might be because people with high income have stressful and unhealthy dietary lifestyle; however, this question is subjective and may lead to response bias (social-desirability bias). ${ }^{11}$

Some behavioral factors were significantly associated with GC, such as smoking status (current, or former, or passive), an average number of sticks, duration, and smokeless tobacco use, habits with smokeless tobacco, and exercise. Compared with nonsmokers, current and passive smokers showed a significant association with GC, which is constant with previous research. ${ }^{12}$ Furthermore, GC risk is more in the previous smokers ( $\mathrm{OR}=2.17$ ) compared with nonsmokers. Also, our study also suggested that GC was directly related to the duration of smoking, i.e., the smokers who smoked for 15 years and more were more likely to have GC risk compared with those who smoked less, ${ }^{12}$ which is consistent with previous studies which produced similar results. ${ }^{13,14}$ Similarly, people with habits of using smokeless tobacco such as bitternut, cigar, Jorda, chewing tobacco leaf, and gul had 2.4 times more risk of developing GC, which is similar to the result of a study that suggested that clarified smokeless tobacco intake represents the highest risk, especially among female patients. ${ }^{15}$ In contrast, exercise habit was found to have a significant protective effect against GC, which is also supported by other studies which produced similar results. ${ }^{16}$ One possible explanation might be that long-term sports habit (as considered vigorous-intensity activity) boosts the immune system function through an increase of the number and activity of natural killer cells, macrophages, and inter- leukins. ${ }^{16}$ On the contrary, the current walking habit was not found to have a protective effect, which might be because the patients only started walking at least 30 minutes daily after being diagnosed with having GC. However, a previous longitudinal study in colon cancer patients found that patients who completed approximately 217 to 282 minutes of walking per week had decreased risk of GC. ${ }^{17}$

The dietary patterns of the participants were also analyzed and found that red meat, fast food, and fatty foods were significantly associated with GC. Patients who consumed red meat regularly were 2.7 times more likely to develop GC $(\mathrm{OR}=2.74)$, which is also supported by previously published studies, ${ }^{18}$ e.g., a study (systematic review and meta-analysis) discovered that high intake of red meat may increase the risk of GC by approximately 35\%. ${ }^{19}$ Besides, another research suggested that red meat and processed meat were positively associated with GC risk as red meat and process meats are the sources of saturated fats, iron, and several mutagens which contribute to the development of GC risk. ${ }^{7}$ Similarly, fast food and fatty food were found to be directly associated with GC risk ( $\mathrm{OR}=3.52$ and $\mathrm{OR}=1.4$, respectively). This is consistent with a recent study that concluded that western cuisines (hamburger, cheeseburger, French fries, fried potatoes, fried chicken, biscuits, rolls ham and bacon, sausage, and cheese) were highly associated with GC risk. ${ }^{20,21}$ In contrast, regular intake of vegetables was found to be significantly protective $(\mathrm{OR}=0.2 .6)$, consistent with a large-scale cohort study which showed a dose-dependent reduction in the risk of GC in patients especially among males with the intake of green leafy vegetables. ${ }^{22-24}$

Our study also analyzed the association between patients' history and GC risks. Patients with previous gastric disease (gastritis, H. pylori infection, etc.) were 1.18 times more likely to develop GC, but our results were not significant. However, our finding is consistent with previous research findings. A systematic review and meta-analysis on previous lung diseases and GC risk also revealed that $H$. pylori disease was a significant risk factor for GC (relative risk $=2.43$ ).${ }^{25}$ Furthermore, family history of any type of cancer was found to have a significant risk in developing GC, which is supported by other studies. $^{25-28}$

Lastly, most of the patients in this study were diagnosed with GC at stage 3 and 4, which further substantiated the need for early identification of risk factors, screening, and early diagnosis (i.e., stage 1 and 2 ).

\section{Conclusion}

The findings of our study suggested a significant association of some dietary and behavioral factors in the development of GC. The study found that people who were consuming red meat regularly were twice more likely to develop GC. Similarly, smoking, fast food and fatty food consumption, and family history of GC were also found to be the risk factors for the development of GC among the Bangladeshi population. In contrast, consumption of vegetables and fruits, regular exercise, and intake of tea and coffee were found to have a protective effect against GC. Early identification of risk 
factors and effective preventive strategies against it as well as promoting protective factors might help to reduce the risk of development and progression of GC.

\section{Funding}

None.

\section{Conflict of Interest}

None declared.

\section{Acknowledgment}

The authors are grateful to the Director of National Institute of Cancer Research and Hospital (NICRH) Professor Dr. Md. Moarraf Hossein and Professor Dr. Nazrina Khatun, Head of the Department of Medical Oncology, for cooperation and support during data collection. And special thanks to the Ethical Committee of NICRH for giving us permission to conduct our research.

\section{References}

1 American Cancer Society. Cancer Facts and Figures 2010. Atlanta, GA: American Cancer Society; 2010

2 American Institute for Cancer Research. Food, nutrition and the prevention of cancer; a global perspective. Washington, DC: American Institute for Cancer Research; 1997

3 Beltz LA, Bayer DK, Moss AL, Simet IM. Mechanisms of cancer prevention by green and black tea polyphenols. Anticancer Agents Med Chem 2006;6(05):389-406

4 Ferlay J, Bray F, Pisani P, et al. GLOBOCAN 2002: Cancer incidence, mortality and prevalence worldwide. IARC Cancer Base no.5, version 2.0. Lyon: IARC Press; 2004

5 Aljebreen AM. Clinico-pathological patterns of colorectal cancer in Saudi Arabia: younger with an advanced stage presentation. Saudi J Gastroenterol 2007;13(02):84-87

6 Hamilton SR. Carcinoma of the stomach and rectum. In: Hamilton SR, Aaltonen LA, eds. Pathology and Genetics of Tumour of the Digestive System. Lyon: IARC Press; 2000:103-142

7 Jemal A, Bray F, Center MM, Ferlay J, Ward E, Forman D. Global cancer statistics. CA Cancer J Clin 2011;61(02):69-90

8 Ahmed S, Banerjea A, Hands RE, Bustin S, Dorudi S. Microarray profiling of colorectal cancer in Bangladeshi patients. Colorectal Dis 2005;7(06):571-575

9 Moore MA, Ariyaratne Y, Badar F, et al. Cancer epidemiology in South Asia - past, present and future. Asian Pac J Cancer Prev 2010;11(Suppl 2):49-66
10 Afroza A, Hasan S, Rukunuzzaman M, Hussain SA, Amin R. Carcinoma- stomach in an 11 years old boy. Mymensingh Med J 2007;16(02, Suppl):70-72

11 Hossain T. Clinicopathological study of stomach carcinoma [MD Thesis]. Dhaka: Bangabandhu Sheikh Mujib Medical University; 2007

12 Keating J, Pater P, Lolohea S, Wickremesekera K. The epidemiology of colorectal cancer: what can we learn from the New Zealand Cancer Registry? N Z Med J 2003;116(1174):U437

13 Rosai J. Gastrointestinal tract. In: Rosai J, ed. Ackerman's Surgical Pathology, 9th ed. Maryland Heights, MO: Mosby Company; 2004:776-825

14 Ayyub MI, Al-Radi AO, Khazeindar AM, Nagi AH, Maniyar IA. Clinicopathological trends in colorectal cancer in a tertiary care hospital. Saudi Med J 2002;23(02):160-163

15 Gomez D, Dalal Z, Raw E, Roberts C, Lyndon PJ. Anatomical distribution of colorectal cancer over a 10 year period in a district general hospital: is there a true "rightward shift"? Postgrad Med J 2004;80(949):667-669

16 Ekem TE, Bahadir B, Gun BD, et al. Colorectal carcinomas: clinicopathologic investigation, correlation with expression of estrogen and progesterone receptors. Turkish J Cancer 2008;38(03):118-122

17 Center MM, Jemal A, Smith RAQ, Ward E. Worldwide variations in colorectal cancer. CA Cancer J Clin 2009;59(06):366-378

18 Obrand DI, Gordon PH. Continued change in the distribution of colorectal carcinoma. Br J Surg 1998;85(02):246-248

19 Howson CP, Hiyama T, Wynder EL. The decline in gastric cancer: epidemiology of an unplanned triumph. Epidemiol Rev 1986;8:1-27

20 Fraser P, Chilvers C, Beral V, Hill MJ. Nitrate and human cancer: a review of the evidence. Int J Epidemiol 1980;9(01):3-11

21 Weisburger JH, Chung FL. Mechanisms of chronic disease causation by nutritional factors and tobacco products and their prevention by tea polyphenols. Food Chem Toxicol 2002;40(08): $1145-1154$

22 Oshima A, Ajiki W, Tanaka H, et al. Significance and usefulness of cancer registries. Int J Clin Oncol 1998;3:343-350

23 Parkin DM, Bray FI, Devesa SS. Cancer burden in the year 2000. The global picture. Eur J Cancer 2001;37(Suppl 8):S4-S66

24 Murray CJ, Lopez AD. Alternative projections of mortality and disability by cause 1990-2020: Global Burden of Disease Study. Lancet 1997;349(9064):1498-1504

25 Hussain SM. Comprehensive update on cancer scenario of Bangladesh. South Asian J Cancer 2013;2(04):279-284

26 IARC. Cancer incidence and mortality worldwide (IARC Cancer Base No.10). LyonInternational Agency for Research on Cancer2011

27 Health Bulletin 2016. Management Information System Directorate General of Health Services (2nd edition).

28 Kim MS, Lee J, Sidransky D. DNA methylation markers in colorectal cancer. Cancer Metastasis Rev 2010;29(01):181-206 